\title{
Genetic analysis of heat stress effects on yield traits, udder health, and fatty acids of Walloon Holstein cows
}

\author{
H. Hammami, ${ }^{\dagger}{ }^{1}$ J. Vandenplas, ${ }^{*} \dagger$ M.-L. Vanrobays, ${ }^{*}$ B. Rekik, $\ddagger$ C. Bastin, ${ }^{*}$ and N. Gengler* \\ ${ }^{*}$ Animal Science Unit, Gembloux Agro-Bio Tech, University of Liege, 5030 Gembloux, Belgium \\ †National Fund for Scientific Research, 1000 Brussels, Belgium \\ $\ddagger$ School of Higher Education in Agricultural of Mateur, TN-7030 Mateur, Tunisia
}

\section{ABSTRACT}

Genetic parameters that considered tolerance for heat stress were estimated for production, udder health, and milk composition traits. Data included 202,733 testday records for milk, fat, and protein yields, fat and protein percentages, somatic cell score (SCS), 10 individual milk fatty acids (FA) predicted by mid-infrared spectrometry, and 7 FA groups. Data were from 34,468 first-lactation Holstein cows in 862 herds in the Walloon region of Belgium and were collected between 2007 and 2010. Test-day records were merged with daily temperature-humidity index (THI) values based on meteorological records from public weather stations. The maximum distance between each farm and its corresponding weather station was $21 \mathrm{~km}$. Linear reaction norm models were used to estimate the intercept and slope responses of 23 traits to increasing THI values. Most yield and FA traits had phenotypic and genetic declines as THI increased, whereas SCS, C18:0, C18:1 cis-9, and 4 FA groups (unsaturated FA, monounsaturated FA, polyunsaturated FA, and long-chain FA) increased with THI. Moreover, the latter traits had the largest slope-to-intercept genetic variance ratios, which indicate that they are more affected by heat stress at high THI levels. Estimates of genetic correlations within trait between cold and hot environments were generally high $(>0.80)$. However, lower estimates $(<$ $=0.67$ ) were found for SCS, fat yield, and C18:1 cis-9, indicating that animals with the highest genetic merit for those traits in cold environments do not necessarily have the highest genetic merit for the same traits in hot environments. Among all traits, C18:1 cis-9 was the most sensitive to heat stress. As this trait is known to reflect body reserve mobilization, using its variations under hot conditions could be a very affordable milk biomarker of heat stress for dairy cattle expressing the equilibrium between intake and mobilization under warm conditions.

Received November 24, 2014

Accepted March 25, 2015

${ }^{1}$ Corresponding author: hedi.hammami@ulg.ac.be
Key words: temperature-humidity index, heat stress, fatty acid, udder health, genetic variation

\section{INTRODUCTION}

Production losses, morbidity, and mortality due to heat stress are increasing concerns in tropical and subtropical regions, but recently also in temperate areas (Renaudeau et al., 2012). Feeding modifications (e.g., increasing feed intake), environmental conditioning (e.g., cooling and shading), and genetic selection for heat tolerance remain the 3 best strategies to alleviate the effects of heat stress on dairy cattle (Renaudeau et al., 2012). Environmental and feeding modifications are specific to each production system and mainly depend on their additional value for improving animal performances, fitness, and well-being compared with their costs. However, genetic improvement of livestock is cost effective by producing permanent and cumulative change (Wall et al., 2010). Selecting purebred or crossbred heat-tolerant animals is an effective management method for heat stress only if high production efficiency can be associated with a capacity to cope with hot and humid conditions.

Knowledge still is lacking about genetic variation for heat tolerance. Genetic selection for regulation of core body temperature is one potential strategy to mitigate effects of heat stress on dairy cows (Dikmen et al., 2012). However, the inheritance of physiological traits (e.g., rectal temperature and pulse) is still not understood well, primarily because of the difficulty and cost of routine accurate measurement of those traits. In contrast, large amounts of data are available on animal performance and weather parameters. Direct measures of an animal's capacity to produce, reproduce, and live under heat stress have been shown to be potentially useful for selecting animals for heat tolerance in tropical and subtropical conditions [e.g., dairy cattle (Ravagnolo and Misztal., 2000; Aguilar et al., 2009; Sánchez et al.., 2009; Boonkum et al., 2011), pigs (Zumbach et al., 2008), and dairy sheep (Finocchiaro et al., 2005)].

Genetic studies of heat stress effects in dairy cattle were based originally on (1) determining a tipping 
point for thermal index after which a linear decline of production occurred and (2) regressing phenotypic performance on remaining points after this threshold to model the additive genetic variance of heat tolerance. Such a modeling approach assumed that all cows had the same threshold and rate of decline in every region and over time. To overcome those limitations, Sánchez et al. (2009) proposed a more realistic approach based on a hierarchical Bayes model in which the threshold and decline rate were assumed to be different and variable for individual cows. However, those assumptions required more complicated and highly parameterized models that could make estimation procedures inefficient.

Few genetic studies on heat stress under temperate climate and production systems currently are available for dairy cattle. Brügemann et al. (2011) and Hammami et al. (2013) reported low thresholds for a temperaturehumidity index (THI) for production traits compared with those reported under tropical and subtropical conditions (Bohmanova et al., 2008; Aguilar et al., 2009; Boonkum et al., 2011). Differences in cow response to changes in the prevailing environment require more consideration of genotype by environment interactions. Environments may be described as discrete units, such as country or region, or measured on a continuous scale using a range of environmental descriptors, such as climate variables (Hammami et al., 2009). Thermal indices, such as a THI, quantify climatic and seasonal effects on animals on a continuous scale. Individual response to each gradient of THI should be better quantified by using reaction norm models, which allow greater flexibility to model genetic variation of heat tolerance across the range of the THI scale without fixing a threshold level. By modeling cow performance as a function of a continuous THI, highly productive individuals with low sensitivity to THI potentially could be identified and selected.

Heat stress conditions have been associated with decreased milk, fat, and protein yields in addition to delayed conception and altered pregnancy rates (Thatcher and Collier, 1986). Nearly all comprehensive studies on genetics of heat tolerance in dairy cattle were conducted in the United States using productive and reproductive data from tropical and subtropical Holstein populations (Ravagnolo and Misztal, 2000; Bohmanova et al., 2008; Aguilar et al., 2009; Boonkum et al., 2011). Heritability estimates for both production and fertility traits were found to increase as a function of THI after a threshold of 72 , which implies that selective improvement of heat tolerance is possible for milk traits (Ravagnolo and Misztal, 2000).

Recently, great interest has been shown in milk fat and its FA profile because of their effects on techno- logical, sensorial, and nutritional properties of milk and dairy products. Most of the C4:0 to C14:0 and almost half of the C16:0 FA in milk are synthesized de novo, whereas the rest of the C16:0 and approximately all long-chain FA originate from blood lipids (Chilliard et al., 2000). Milk FA vary phenotypically and genetically across the lactation and have moderate to high heritabilities, which indicates that they could be changed by genetic selection (Bastin et al., 2013). Milk FA profile was also found to be a potential indicator of cow energy balance (Bastin et al., 2012) and methane emission (Chilliard et al., 2009). Although studies based on controlled experiments or a limited number of animals under a few commercial conditions reported that milk fat composition differed between seasons and weather conditions (Renna et al., 2010), no studies have evaluated genetic, phenotypic, and inheritance variation of FA over a continuous range of climate conditions (e.g., a THI scale). Such studies could provide added knowledge on the individual response to weather parameters (climate change) for milk FA profile and investigate the potential use of those milk biomarkers as indicators of heat stress. The objectives of the current genetic analysis were (1) to evaluate heat stress effects on yield traits (milk, fat, and protein yields and fat and protein percentages), udder health (SCS), and milk quality (FA profile) and (2) to assess the potential of milk FA as biomarkers for dairy cattle resilience to climate change.

\section{MATERIALS AND METHODS}

\section{Data}

The data included 202,733 test-day (TD) records of yield, milk content, and FA traits that had been collected between 2007 and 2010 from 34,468 primiparous Holstein cows in 862 herds. Records for daily milk, fat, and protein yields, fat and protein percentages, and SCS were collected by the Walloon Breeding Association (AWE, Ciney, Belgium). Additionally, 10 individual milk FA (C4:0, C6:0, C8:0, C10:0, C12:0, C14:0, C16:0, C17:0, C18:0, and C18:1 cis-9) and 7 FA groups [SFA, MUFA, PUFA, unsaturated FA (UFA), short-chain FA (SCFA), medium-chain FA (MCFA), and long-chain FA (LCFA)] were considered as performance traits. The groups of FA were defined similarly to those in Bastin et al. (2013). Saturated FA includes C4:0, C6:0, C8:0, C10:0, C12:0, C12:0 iso, C12:0 anteiso, C13:0 iso, C14:0, C14:0 iso, C14:0 anteiso, C15:0, $\mathrm{C} 15: 0$ iso, C16:0, C16:0 iso, C16:0 anteiso, C17:0, C17:0 iso, C17:0 anteiso, C18:0, C19:0, C20:0, and C22:0. The group of MUFA includes C10:1, C12:1 cis, C14:1 cis, C16:1 cis, C16:1 trans, C18:1 cis-9, C18:1 cis-11, C18:1 cis-12, C18:1 trans-6-11, C18:1 trans-12-14, C18:1 
cis- $13+$ cis- $14+$ trans- $16, \mathrm{C} 20: 1$ cis-9, and C20:1 cis11. Polyunsaturated FA includes C18:2 cis-9,trans-13, C18:2 trans-8,cis-12, C18:2 cis-9,trans-12, C18:2 trans8,cis-13, C18:2 trans-11,cis-15, C18:2 trans-9,cis-12, C18:2 cis-9,cis-12, C18:2 cis-9,trans-11, C18:3 cis-9,cis12,cis-15, C20:3 (n-6), C20:4 (n-6), C20:5 eicosapentaenoic acid (n-3), and C22:5 docosapentaenoic acid. Unsaturated FA comprises MUFA and PUFA. Shortchain FA consist of FA with 4 to 10 carbons, MCFA of 12 to 16 carbons, and LCFA of $>16$ carbons.

Using the Walloon mid-infrared spectral dataset, the FA traits were predicted with the updated calibration equations presented by Soyeurt et al. (2011). Records were retained for lactations with at least $3 \mathrm{FA}$ TD records from cows with known sires that had $>10$ daughters and a minimum of 5 cows per herd TD level was required. Pedigree data were traced back to 1985 and were extracted from the official Walloon genetic evaluation data.

Meteorological data were obtained from the Royal Meteorological Institute (IRM, Brussels, Belgium) and included the daily recordings of 4 weather stations in the Walloon region of Belgium. Each record included daily minimum, maximum, and mean outside temperature, mean daily relative humidity, and mean daily rain. A daily THI was computed using the following formula (NRC, 1971):

$\mathrm{THI}=(1.8 T+32)-[(0.55-0.0055 \mathrm{RH})(1.8 T-26)]$,

where $T$ is mean daily temperature in degrees Celsius and $\mathrm{RH}$ is the mean daily relative humidity as a percentage.

Each TD record with yield traits, SCS, and FA traits was assigned to the average THI from the nearest weather station $3 \mathrm{~d}$ before the TD. Distances between a herd and its corresponding weather station averaged 13 $\mathrm{km}$, with a minimum of $2 \mathrm{~km}$ and a maximum of $21 \mathrm{~km}$.

\section{Statistical Models}

The sensitivity of animals to climate conditions (THI) was modeled using a reaction norm model, where each studied trait was expressed as a function of THI. Each animal was assumed to have a general (intercept) EBV and a specific (slope) EBV for tolerance to heat stress on the THI scale.

Nonlinear reaction norm models using polynomial functions might fit better the phenotypic and genetic variation of production traits along the range of temperatures and THI values in Germany (Brügemann et al., 2011) and Spain (Carabaño et al., 2014). Those models could also be more accurate than linear reac- tion norm models for FA traits. However, in our study, equilibrium between the computational complexity and the clear biological interpretation given the large number of studied traits was prioritized. Additionally, a preliminary analysis combining large protein yield data from 4 important European Holstein populations and using cubic Legendre polynomial regression coefficients on standardized THI scale showed that fixed and linear terms together explained more than $95 \%$ of the total variation for all populations (Hammami et al., 2014). Due to both cited facts, the linear reaction norm model was chosen here as simple but still efficient strategy.

The model to estimate genetic parameters for each of the 23 traits separately was

$$
\mathbf{y}=\mathbf{X b}+\mathbf{Q}_{\mathrm{hs}} \mathbf{W t}+\mathbf{Q}_{\mathrm{hs}}\left(\mathbf{Z}_{1} \mathbf{a}+\mathbf{Z}_{2} \mathbf{p}\right)+\mathbf{e},
$$

where $\mathbf{y}$ is a vector of observations; $\mathbf{b}$ is a vector of fixed effects [herd-TD, minor lactation stage (classes of 5 DIM), gestation stage, and major lactation stage (classes of 73 DIM)-calving age-calving season]; $\mathbf{t}$ is a vector of the fixed first-order Legendre polynomial coefficients to model effect of population mean for THI; $\mathbf{Q}_{\mathrm{hs}}$ is the covariate matrix for first-order Legendre polynomials for standardized THI in the interval -1 to 1 , which corresponds to an interval of 18 to 75 $\left[q_{\mathrm{hs} 0}=1\right.$ and $q_{\mathrm{hs} 1}=x$, where hs indicates heat-specific and $x=-1+2($ THI -18$) /(75-18)] ;$ a is a vector of random regression coefficients for additive genetic (AG) effects; $\mathbf{p}$ is a vector of random regression coefficients for permanent environmental (PE) effects; $\mathbf{X}, \mathbf{W}, \mathbf{Z}_{1}$, and $\mathbf{Z}_{2}$ are incidence matrices that assign observations to effects; and $\mathbf{e}$ is the vector of residuals. Genetic parameters were estimated for each trait at each point of the THI range (18 to 75 ).

The variance and covariance structure was

$$
\operatorname{Var}\left[\begin{array}{l}
\mathbf{a} \\
\mathbf{p} \\
\mathbf{e}
\end{array}\right]=\left[\begin{array}{ccc}
\mathbf{A} \otimes \mathbf{K}_{a} & \mathbf{0} & \mathbf{0} \\
\mathbf{0} & \mathbf{I} \otimes \mathbf{K}_{p} & \mathbf{0} \\
\mathbf{0} & \mathbf{0} & \mathbf{R}
\end{array}\right],
$$

where $\otimes$ denotes Kronecker product; $\mathbf{A}$ is the AG relationship matrix; $\mathbf{I}$ is an identity matrix; $\mathbf{K}_{a}$ and $\mathbf{K}_{p}$ are matrices of coefficients of the covariance function on the standardized THI scale for AG and PE, respectively; and $\mathbf{R}$ is a residual (co)variance matrix. Then,

$$
\mathrm{K}_{a}=\left[\begin{array}{cc}
\sigma_{a_{0}}^{2} & \sigma_{a_{0} a_{\mathrm{hs}}} \\
\sigma_{a_{0} a_{\mathrm{hs}}} & \sigma_{a_{\mathrm{hs}}}^{2}
\end{array}\right]
$$

and 


$$
\mathrm{K}_{p}=\left[\begin{array}{cc}
\sigma_{p_{0}}^{2} & \sigma_{p_{0} p_{\mathrm{hs}}} \\
\sigma_{p_{0} p_{\mathrm{hs}}} & \sigma_{p_{\mathrm{hs}}}^{2}
\end{array}\right],
$$

where $\sigma_{a_{0}}^{2}, \sigma_{a_{\mathrm{hs}}}^{2}, \sigma_{p_{0}}^{2}$, and $\sigma_{p_{\mathrm{hs}}}^{2}$ were variances for intercept and slope for $\mathrm{AG}$ and $\mathrm{PE}$, respectively, and $\sigma_{a_{0} a_{\mathrm{hs}}}$ and $\sigma_{p_{0} p_{\mathrm{hs}}}$ were covariances between intercept and slope for AG and PE, respectively. Variance components were estimated using REMLF90 (Misztal et al., 2002).

Estimation of genetic correlations among different traits based on a multitrait model or even on many combinations of bivariate models was computationally difficult and impractical because of the number of traits. Therefore, genetic correlations among different traits across different points of the THI scale were approximated following Calo et al. (1973). Approximate genetic correlations $\left(\hat{r}_{g_{1_{i}, 2_{j}}}\right)$ between trait 1 at THI $i$ and trait 2 at THI $j$ were calculated as

$$
\hat{r}_{g_{1_{i}, 2_{j}}}=\frac{\sqrt{\sum \mathrm{REL}_{1 i} \mathrm{REL}_{2 j}}}{\sum\left(\mathrm{REL}_{1 i} \mathrm{REL}_{2 j}\right)}\left(r 1_{i} 2_{j}\right),
$$

where $\mathrm{REL}_{1 i}$ and $\mathrm{REL}_{2 j}$ are reliabilities of trait 1 at THI $i$ and trait 2 at THI $j$, respectively, and $r 1_{i}, 2_{j}$ is the correlation between EBV of trait 1 at THI $i$ and EBV of trait 2 at THI $j$. Approximate genetic correlations were calculated for pairwise traits across the THI range.

\section{RESULTS AND DISCUSSION}

\section{Phenotypic Variation Within the THI Scale}

Table 1 shows average TD records across the THI scale before and after THI point of 62 . The THI point of 62 was selected because it corresponds to the same range of threshold points estimated for production traits in neighboring German and Luxembourg Holstein populations (Brügemann et al., 2011; Hammami et al., 2013; Lambertz et al., 2014). Average daily yields were lower above this THI point for all production traits, whereas the average daily SCS was higher for the same highest THI values. The decline of daily production and, conversely, the increase of SCS on the phenotypic scale observed at high THI values in our study (Table 1) agreed with most previous evaluations of THI effects on production traits (e.g., Hammami et al., 2013).

Similar to production traits, the trend that phenotypic values decreased with increasing THI values was also observed for almost all individual FA, except for
C18:0 and C18:1 cis-9 contents, which increased as THI increased (Table 1). Contrary to production traits and most individual FA, the increase of THI was associated with an increase of the daily contents for almost all FA groups (UFA, MUFA, PUFA, and LCFA). Their proportions of variation below and above THI 62 were $4.2 \%$ for UFA, $4.0 \%$ for MUFA, $6.1 \%$ for PUFA, and $5.3 \%$ for LCFA. The decrease in content of SCFA and MCFA and the content increase of LCFA as THI increased (Table 1) were in line with results presented by Richardson et al. (1961). This fact indicates that synthesis of SCFA and MCFA in the mammary gland cells is reduced when cows are heat stressed. The decrease of SFA content and the increase of UFA, MUFA, and PUFA contents at high THI values were also reported by Renna et al. (2010) when evaluating the exposure of dairy cows to heat stress under alpine grazing conditions. Those FA trends across THI range could also reflect different feeding patterns across seasons (e.g., more forage-based diets in summer could lead to a higher content of UFA). Most of the cited studies (e.g., Simensen, 1976; Renna et al., 2010) were designed mainly to evaluate general seasonal effect (e.g., winter vs. summer) on FA profiles based on data from a few individuals with little or no environmental descriptors (i.e., daily climate conditions). Richardson et al. (1961) observed lower content of SCFA and MCFA and higher content of LCFA at high THI. Although the exact mechanisms behind the specific variation of some FA during heat stress are not entirely clear, it is thought that increased body temperature during heat stress might have a direct effect on fat synthesis by the mammary gland. Richardson et al. (1961) reported that synthesis of SCFA and MCFA in the mammary gland is reduced when cows are heat stressed. They also stated that the increase of LCFA content could be attributed to their high melting points (e.g., 63 and $69^{\circ} \mathrm{C}$ for $\mathrm{C} 16: 0$ and $\mathrm{C} 18: 0$, respectively), whereas the decrease in SCFA and MCFA content could be attributed to their lower melting points $(-1.5$ and $47^{\circ} \mathrm{C}$ for $\mathrm{C} 6: 0$ and $\mathrm{C} 12: 0$, respectively). The melting point is primarily influenced by the degree of the FA saturation and to a lesser extent by the length of the carbon chain. An alternative hypothesis suggests that the high proportion of LCFA is a result of lipomobilization, which induces a reduction in the synthesis of SCFA and MCFA in the mammary gland cells of heat-stressed cows (Smith et al., 1983). Nevertheless, those authors did not clearly attributed the changes of milk FA to a direct effect of heat stress, and stated that they could be associated with the lower forage intake commonly occurring during summer, the latter being also a reaction of the cows to higher THI.

Highest THI values (THI $\geq 62$ ) when cows could suffer from heat stress were mainly observed during 
Table 1. Mean and standard deviation (SD) of test day records below and above a temperature-humidity index (THI) level of 62

\begin{tabular}{|c|c|c|c|c|}
\hline \multirow[b]{2}{*}{ Trait } & \multicolumn{2}{|c|}{ THI $<62$} & \multicolumn{2}{|c|}{$\mathrm{THI} \geq 62$} \\
\hline & Mean & $\mathrm{SD}$ & Mean & $\mathrm{SD}$ \\
\hline \multicolumn{5}{|c|}{ Production trait } \\
\hline Milk (kg) & 23.43 & 6.10 & 22.47 & 5.67 \\
\hline Fat $(\mathrm{kg})$ & 0.93 & 0.24 & 0.86 & 0.21 \\
\hline Protein (kg) & 0.78 & 0.19 & 0.74 & 0.18 \\
\hline Fat $(\%)$ & 4.02 & 0.65 & 3.87 & 0.62 \\
\hline Protein (\%) & 3.36 & 0.35 & 3.34 & 0.32 \\
\hline SCS & 2.55 & 1.53 & 2.73 & 1.52 \\
\hline \multicolumn{5}{|c|}{ Individual FA ( $\mathrm{g} / \mathrm{dL}$ of milk) } \\
\hline $\mathrm{C} 4: 0$ & 0.104 & 0.023 & 0.099 & 0.023 \\
\hline $\mathrm{C} 6: 0$ & 0.074 & 0.016 & 0.068 & 0.016 \\
\hline $\mathrm{C} 8: 0$ & 0.046 & 0.011 & 0.041 & 0.011 \\
\hline C10:0 & 0.109 & 0.031 & 0.097 & 0.029 \\
\hline C12:0 & 0.134 & 0.040 & 0.118 & 0.037 \\
\hline C14:0 & 0.465 & 0.108 & 0.426 & 0.100 \\
\hline C16:0 & 1.245 & 0.315 & 1.112 & 0.280 \\
\hline $\mathrm{C} 17: 0$ & 0.030 & 0.006 & 0.028 & 0.006 \\
\hline C18:0 & 0.402 & 0.110 & 0.419 & 0.114 \\
\hline C18:1 cis-9 & 0.796 & 0.207 & 0.821 & 0.202 \\
\hline \multicolumn{5}{|c|}{ FA $\operatorname{group}^{1}(\mathrm{~g} / \mathrm{dL}$ of milk$)$} \\
\hline UFA & 1.295 & 0.289 & 1.349 & 0.291 \\
\hline SFA & 2.795 & 0.576 & 2.590 & 0.547 \\
\hline MUFA & 1.117 & 0.261 & 1.162 & 0.260 \\
\hline PUFA & 0.164 & 0.040 & 0.174 & 0.037 \\
\hline SCFA & 0.349 & 0.077 & 0.317 & 0.075 \\
\hline MCFA & 2.143 & 0.489 & 1.938 & 0.446 \\
\hline LCFA & 1.602 & 0.383 & 1.687 & 0.392 \\
\hline
\end{tabular}

${ }^{1} \mathrm{UFA}=$ unsaturated FA; SCFA = short-chain FA; MCFA = medium-chain FA; LCFA = long-chain FA.

summer but also in some spring and autumn days. The highest extreme THI value of 75 (Figure 1) corresponded to $27.2^{\circ} \mathrm{C}$ and $60 \% \mathrm{RH}$. The proportion of TD recorded under high extreme temperature is limited even though a certain proportion of the data $(>16 \%)$ was recorded under climate conditions where THI $\geq 62$ (Figure 1). Bohmanova et al. (2008) used 56 million TD milk records where only 10,7 , and $27 \%$ of TD records were obtained on days with thermal stress above their threshold point (THI >72) in the United States national, northeast, and southeast data sets.

\section{Variance Component and Heritability Estimates}

Slope-to-intercept variance ratios for $A G$ effects $\left(\sigma_{a_{\mathrm{hs}}}^{2} / \sigma_{a_{0}}^{2}\right)$ varied among traits (Table 2 ). For most individual $\mathrm{FA}$, the ratios were small and around 0.03 . Yield traits, SCS, and 4 FA traits (C18:1 cis-9, UFA, MUFA, and LCFA) had the largest ratios (0.05 to 0.11), which indicates that those traits are more affected by heat stress at high THI.

Magnitude of genotype by environment interaction can be determined from $\sigma_{a_{\mathrm{hs}}}^{2} / \sigma_{a_{0}}^{2}$ from a reaction norm model (Kolmodin and Bijma, 2004). Those authors re- ported that a small ratio indicates limited genotype by environment interaction, whereas a larger ratio corresponds to an accentuated genotype by environment interaction where the environmental component has a large effect on selection response.

The PE slope-to-intercept variance ratios $\left(\sigma_{p_{\mathrm{hs}}}^{2} / \sigma_{p_{0}}^{2}\right)$ were much larger than their corresponding AG ratios for all traits (Table 2), especially for FA traits. The highest ratio was found for $\mathrm{C} 18: 1$ cis-9 (0.66) followed by MUFA (0.59), UFA (0.58), and LCFA (0.57). Ratios ranged from 0.31 to 0.45 for other individual FA and were 0.35 for fat percentage and 0.36 for protein percentage. Lowest ratios were found for milk, fat, and protein yields, and SCS (0.16 to 0.20). These results indicate that milk composition, specifically FA profile, is modified under high THI and that individual sensitivity to heat stress for almost all traits is more environmental than genetic. Increased C18:1 cis-9 content in milk for heat-stressed cows (Table 1) could be the result of reduced feed intake and nutrient absorption, which would decrease energy balance. Barber et al. (1997) reported that higher proportions of C18:0 and C18:1 cis-9 were observed when lipolysis was high (i.e., when the cow is in negative energy balance). 


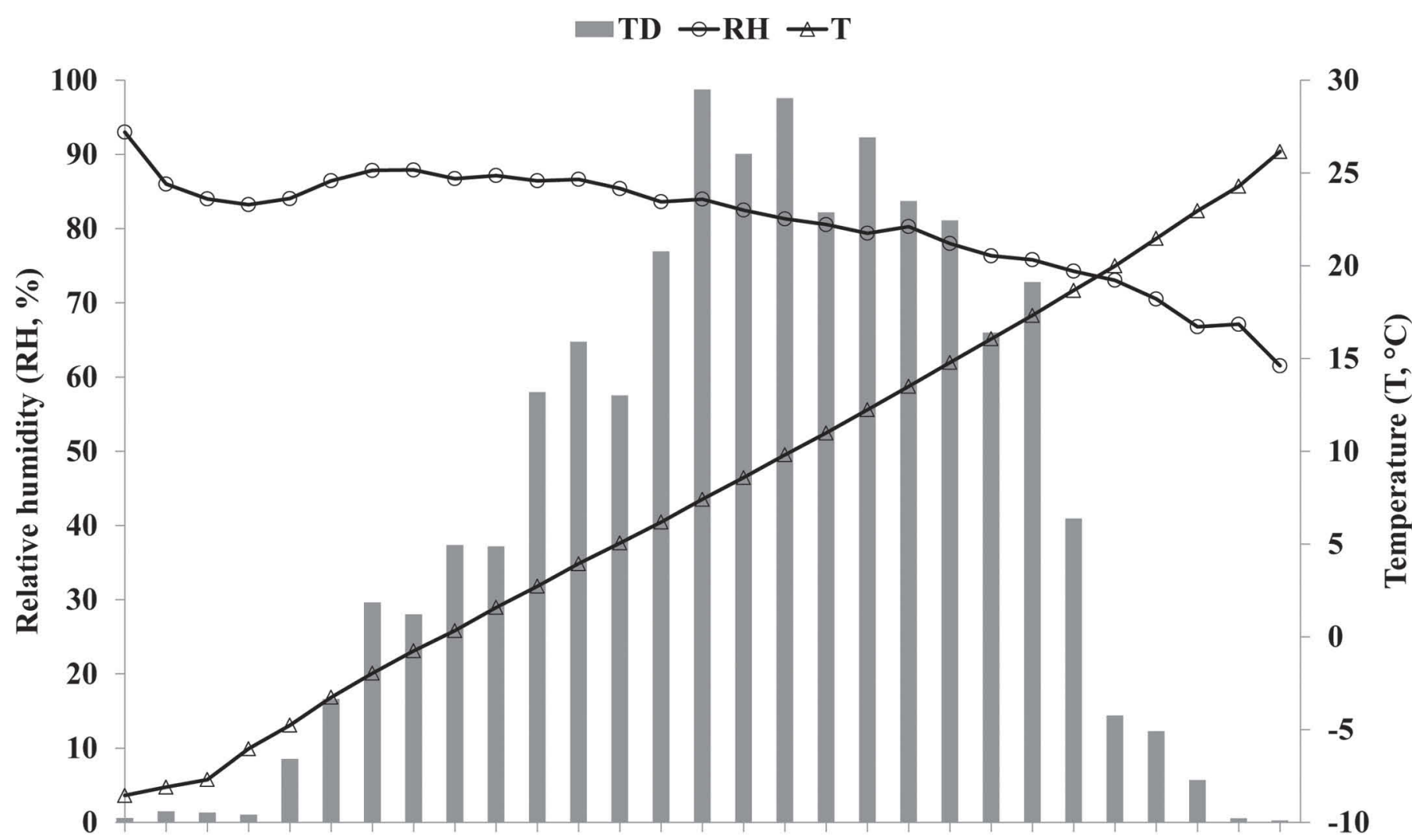

1820222426283032343638404244464850525456586062646668707274 THI

Figure 1. Number of test-day $(\mathrm{TD})$ records $(\times 100)$ per temperature-humidity index $(\mathrm{THI})$ scale and average temperature $\left(\mathrm{T},{ }^{\circ} \mathrm{C}\right)$ and relative humidity $(\mathrm{RH}, \%)$ for classes of 2 THI points.

The AG correlation (Table $2 ; r_{a_{0}, a_{\mathrm{hs}}}$ ) was negative for all yield traits and ranged from -0.15 for protein percentage to -0.28 for milk yield, which was lower than estimates of Aguilar et al. (2009) but in the same range found for milk yield (-0.21) by Boonkum et al. (2011). Correspondent correlation for SCS was positive (0.25). High THI has been associated with increased SCS in several studies (Simensen, 1976; Hammami et al., 2013; Lambertz et al., 2014). Lambertz et al. (2014) reported an increase for both pastured cows and those in indoor housing, but Simensen (1976) found a more pronounced increase in SCC in summer for pastured cows than for those in indoor housing and concluded that the increase could not be directly related to environmental temperature per se. An antagonistic relationship also was found for SFA $\left(r_{a_{0}, a_{\mathrm{hs}}}\right.$ of -0.39$)$ and its individual FA (e.g., -0.43 for C16:0 and -0.35 for C17:0) and for MCFA $\left(r_{a_{0}, a_{\mathrm{hs}}}\right.$ of -0.29 ; a range of -0.20 to -0.43 for C12:0 to C17:0). A moderate positive relationship $\left(r_{a_{0}, a_{\mathrm{hs}}}\right.$ of 0.38$)$ was observed for PUFA. Correlations were positive for
LCFA and its individual FA (C18:0 and C18:1 cis-9), and only slight and weak relationships were found for SCFA and the remaining FA traits. The rather moderate negative AG correlations for yield traits as well as for SFA, MCFA, and their individual FA suggest that cows with high performance for those traits under low THI conditions may show a larger decline in performance under heat stress. Thus, those traits are antagonistic to heat tolerance, and selection for them without considering heat tolerance would impair adaptation of individuals to heat stress. Kolmodin and Bijma (2004) explained that a negative genetic correlation between intercept and slope of a reaction norm model results from selection for high yield in a nonlimiting environment, which leads to increased environmental sensitivity. Conversely, the positive genetic correlation between intercept and slope for SCS and some FA groups and their individual FA (Table 2) indicates that individuals with high performance for those traits are also highly sensitive to increased THI. Kolmodin and Bijma (2004) reported that a positive correlation between level and 
Table 2. Variance (and covariance) component estimates, ratios, and correlations (r) between intercept (0) and slope (hs) for additive genetic $(a)$ and permanent environmental $(p)$ effects and estimates of daily heritability $\left(\mathrm{h}^{2}\right)$

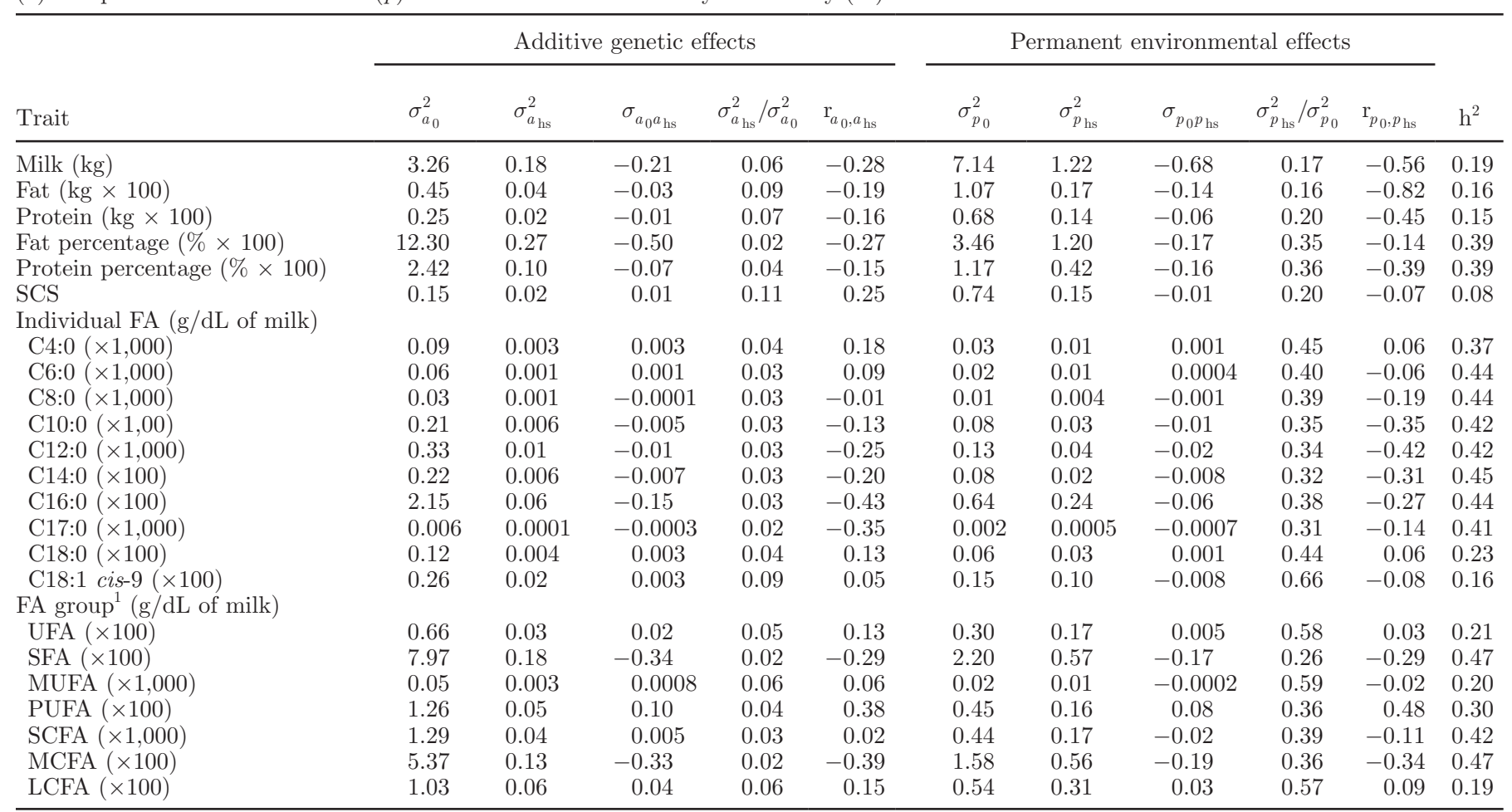

${ }^{1} \mathrm{UFA}=$ unsaturated FA; SCFA = short-chain FA; MCFA = medium-chain FA; LCFA = long-chain FA.

slope results in a higher performance response in a nonlimiting selection environment than in a limiting selection environment.

The pattern for PE correlations $\left(r_{p_{0}, p_{\mathrm{hs}}}\right)$ was similar to that for AG correlations for most traits (Table 2). However, negative PE correlations were substantially larger for yield traits $(-0.14$ to -0.82$)$ and individual medium-chain FA (e.g., a range of -0.27 to -0.42 for C12:0 to C16:0) compared with AG correlations. Although the PE correlation for PUFA was moderately positive (0.48), PE correlations for other traits with positive AG correlations were reduced or slightly negative. Higher $r_{p_{0}, p_{\mathrm{hs}}}$ indicate that cow response to heat stress is mostly environmental. The high negative correlations for yield traits and individual medium-chain individual FA indicate that cow performance under the studied environmental conditions was more unsteady for those traits than for C18:0, C18:1 cis-9, LCFA, PUFA, and MUFA. Nevertheless, climate-forage interaction should be considered because (1) cows are mostly grazed outdoors during spring and summer and (2) most PUFA, LCFA, and their major individual FA are derived from digestion and absorption of dietary fat rather than from de novo synthesis as found for SCFA and MCFA (Bastin et al., 2013).
Our study is the first investigation of heat stress effects on conventional traits and milk FA profile using a large milk-component data set linked to environmental daily THI for each herd TD during the entire lactation of each cow. The current study is only based on primiparous records. Records from multiparous cows will be included in future investigations. When evaluating the genetic variation of production traits under heat stress conditions, Aguilar et al. (2009) found that third parity cows were more susceptible to heat stress than the primiparous cows. The trend of genetic variation of heat stress for FA traits among multiple lactations could be similar but has to be evaluated. However, the lack of sufficient FA records from later parities in the current data set was the major cause to the restriction to records from primiparous cows in the current study.

Mean heritability estimates across THI range (Table 2 ) were in the same range as daily estimates reported by Bastin et al. (2013), who used models similar to those in our study but ignored individual reaction norm to heat stress. Figure 2 shows estimated TD heritabilities by THI. The lowest estimates $(<0.10)$ were found for SCS and moderate estimates (0.13 to 0.25$)$ were found for milk, fat, and protein yield, C18:0, C18:1 cis-9, UFA, MUFA, and LCFA; for the remaining traits, heritability estimates were $>0.25$. Heritability estimates tended 
to decrease slightly at high THI for traits with high heritability (e.g., component percentage and most individual FA). However, stable heritability estimates over the THI range characterized traits that were moderately heritable (e.g., LCFA, MUFA, and UFA). A slight increase in heritability estimates as THI increased was found only for SCS, C18:1 cis-9, PUFA, and fat yield. Heritability curves for production traits as a function of THI varied in the literature (Ravagnolo and Misztal, 2000; Brügemann et al., 2011). However, comparison of estimates from different studies is difficult because of differences in data (e.g., population size, breed, and parity) as well as models and their assumptions (e.g., repeatability, reaction norm, and fixed or heterogonous thresholds).

\section{Correlations Across THI Range}

Within Trait. Estimates of genetic correlations between adjacent THI were consistently high $(>0.90)$ for all traits but were lower between THI that were further apart (not shown). Estimates of correlations between a THI of 25 (cold environment) and other THI are shown in Figure 3. For all traits except SCS, the estimates of genetic correlation was $>0.80$ for THI of $\leq 62$ $\left(T=17.3^{\circ} \mathrm{C}\right.$ and $\left.\mathrm{RH}=76 \%\right)$ and then began to decrease as THI increased. The decrease in genetic correlations for THI of $>62$ was different among traits; the lowest correlations at THI of 75 (extremely hot conditions) were 0.64 for SCS and fat yield and 0.67 for C18:1 cis-9. A similar but not as sharp decrease was also found for milk and protein yields, MUFA, LCFA, and UFA, but their genetic correlations at THI of 75 were much closer to 0.80 . For other traits, correlations generally remained very high (around 0.90) across the THI range. Low estimates of genetic correlations $(<0.80)$ between low and high THI for SCS, fat yield, and C18:1 cis-9 indicate that animals with the highest genetic merit for those traits in cold environments do not necessarily have the highest genetic merit for those traits in hot environments and that genes are expressed differently depending on THI. Zwald et al. (2003) investigated several climatic variables when identifying factors related to genotype by environment interactions in international dairy sire evaluations for milk yield. They reported that heritabilities for milk yield estimated from herds in hot climates were lower than those from herds in temperate climates. Hammami et al. (2008) found considerable reranking of EBV for milk yield between Luxembourg (temperate climate) and Tunisia (hot and humid climate) for Holstein sires. The estimates of genetic correlations of $>0.80$ between low and extremely high THI for most traits in our study suggest no major ranking of sires under production systems in the Walloon region of Belgium. However, the THI range was restricted, only limited data were available for extremely high THI, and no reference is available for comparison, particularly for FA profile traits and udder health (SCS). Joint analysis of similar traits from other countries with larger THI ranges, especially countries in hot climates and with animals that have good genetic ties to the Walloon Holstein population, would be beneficial for validating the estimates of genetic correlations and confirming the magnitude of genotype by environment interaction due to heat stress.

The PE correlations between THI followed a pattern similar to that for genetic correlations. For all traits, PE correlations were high between adjacent THI (not shown) but were markedly lower and declined substantially as THI were further apart (Table 3 ). The low positive correlations for extreme THI scale $\left(27.2^{\circ} \mathrm{C}\right.$ and $60 \% \mathrm{RH})$ estimated for protein percentage, SCS, and most FA traits show that those traits are severely affected under high THI conditions and that cows are better able to express milk, fat, and protein yields persistently across the THI range. Four FA traits had negative PE correlations between THI of 25 and 75 ; the largest negative correlation was -0.20 for $\mathrm{C} 18: 1$ cis-9.

Between Traits. Approximate genetic correlations between TD milk yield and other traits across the THI range are shown in Figure 4. Genetic correlations were highly positive between milk yield and protein and fat yields and slightly positive between milk yield and SCS, whereas relationships between milk yield and fat and protein percentages and all FA traits were negative. Estimates averaged across the THI range were in the same range as correlations reported by Bastin et al. (2013). Approximate genetic correlations between milk yield and fat and protein yields, fat and protein percentages, and SCS generally were stable and did not change much across the THI range. Estimates between milk yield and almost all individual FA were also relatively constant throughout most of the THI range but did slightly increase at extreme THI. The exception was the correlation between milk yield and C18:1 cis9, which decreased first markedly and then gradually as THI increased. Patterns for FA groups were similar and strongly reflected the patterns of their individual FA. No associations between milk yield and other traits across the THI range were found except for C18:1 cis-9, UFA, and MUFA. The decline in correlations with milk yield for those traits as THI diverged can be attributed to antagonistic pleiotropy.

Among traits, C18:1 cis-9 and udder health (SCS) were the most sensitive to variation in THI. They had the highest AG slope-to-intercept variance ratios 


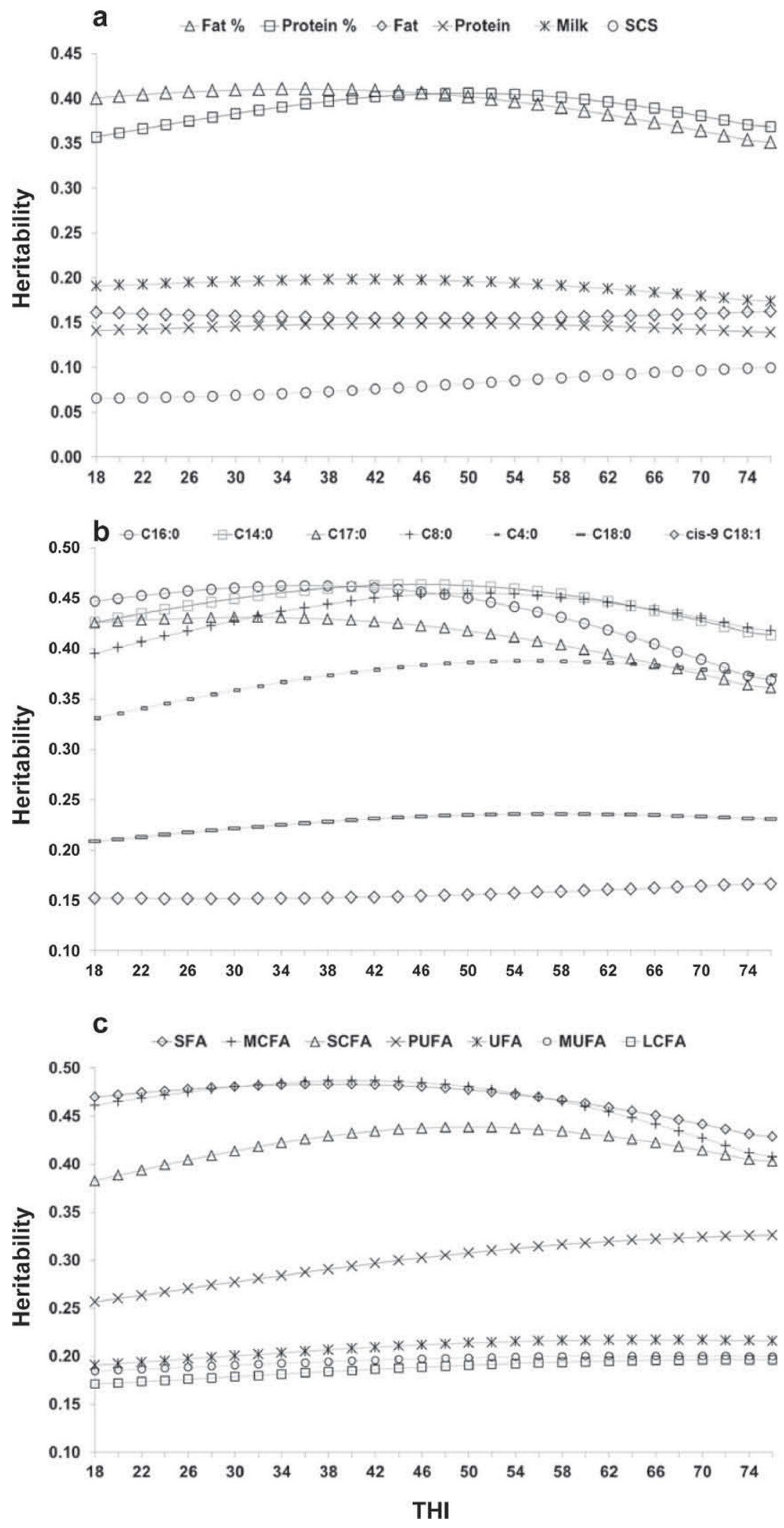

Figure 2. Estimated test-day heritability for (a) production traits (fat and protein percentages, fat, protein, and milk yields, and SCS), (b) individual FA (C16:0, C14:0, C17:0, C12:0, C8:0, C6:0, C10:0, C4:0, C18:0, and C18:1 cis-9), and (c) FA groups [medium-chain FA (MCFA), short-chain FA (SCFA), unsaturated FA (UFA), and long-chain FA (LCFA)] by temperature-humidity index (THI). 
a

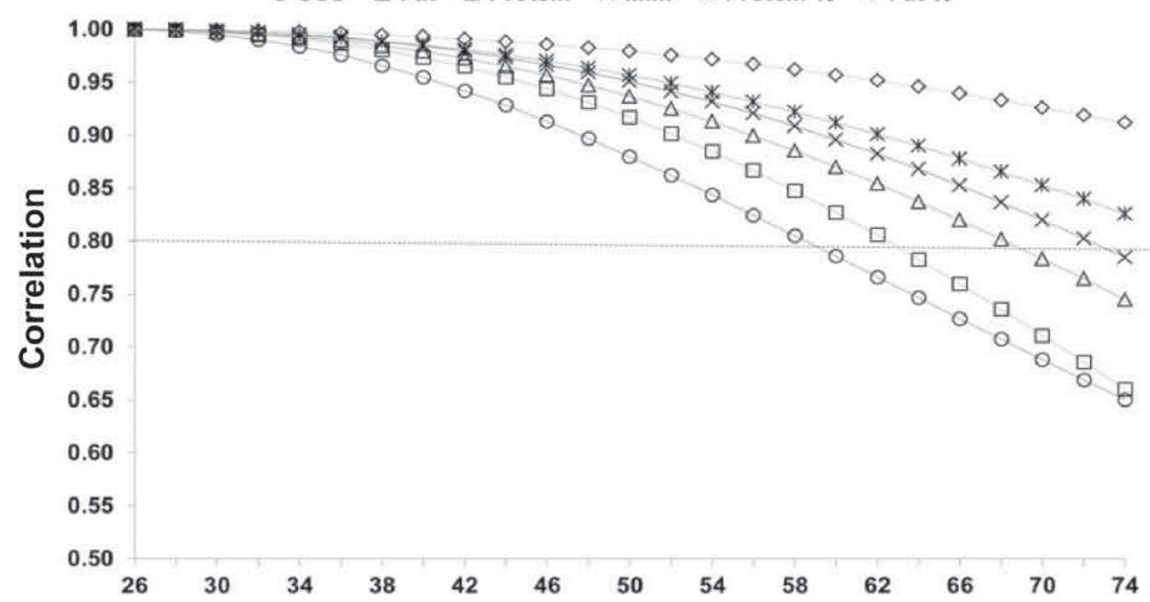

b

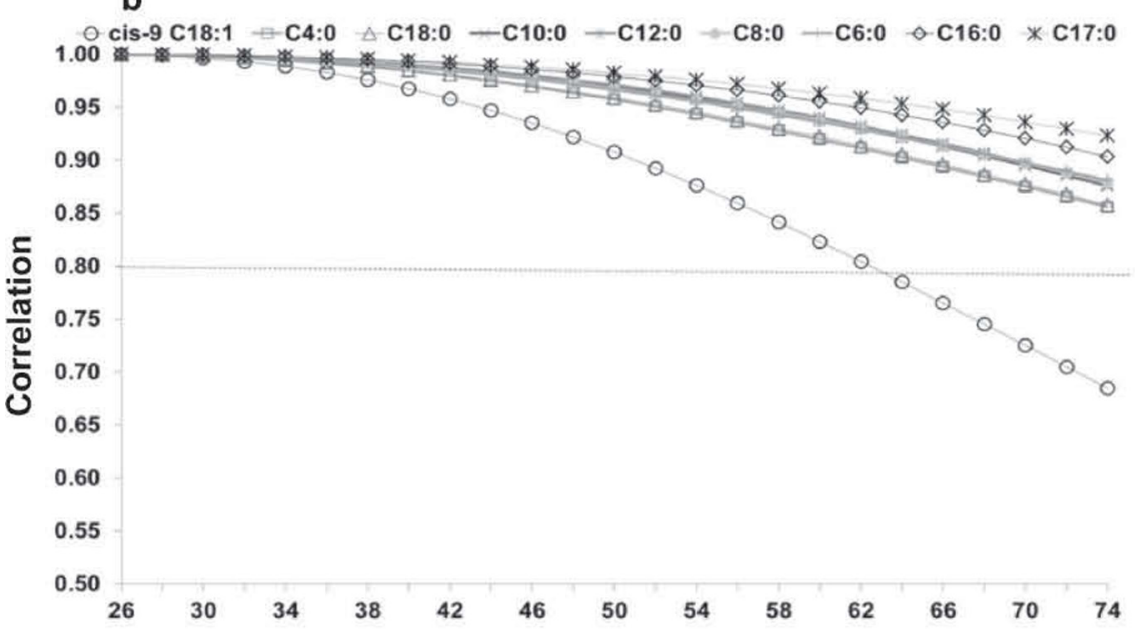

C $\rightarrow$ MUFA $\square$ LCFA $\triangle$ UFA $\leadsto$ PUFA $*$ SCFA - MCFA $\oplus$ SFA

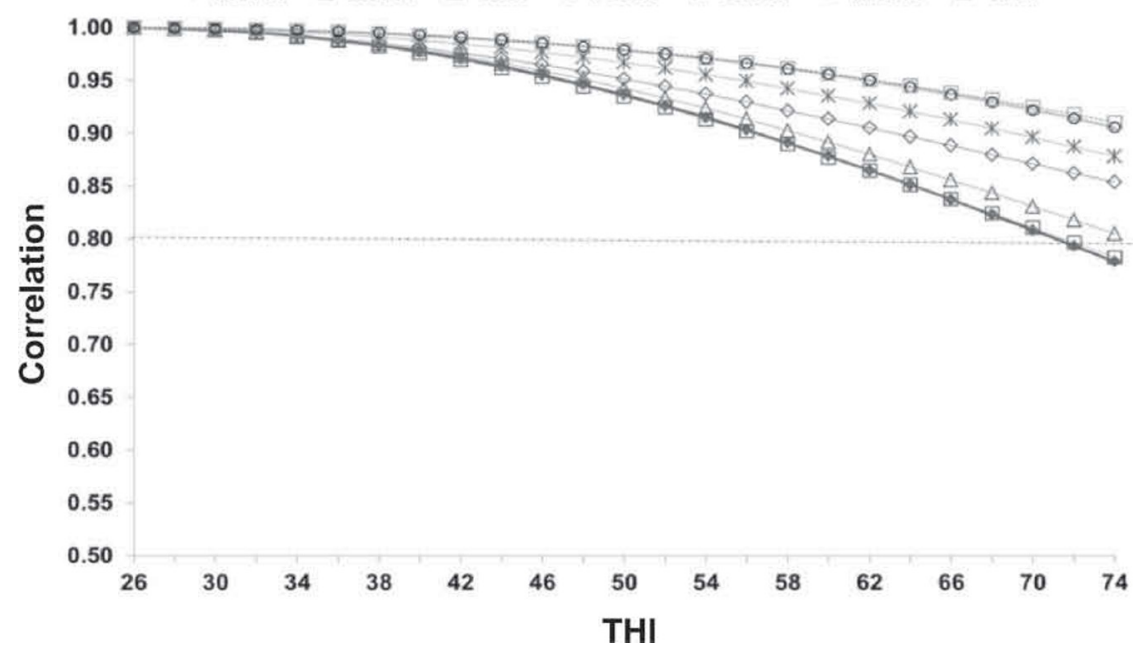

Figure 3. Genetic correlations between a temperature-humidity index (THI) of 25 and other THI for test-day (a) conventional production traits (SCS, fat, protein, and milk yields, protein and fat and percentages), (b) individual FA (C18:1 cis-9, C4:0, C18:0, C10:0, C12:0, C8:0, C6:0, C14:0, C16:0, and C17:0), and (c) FA groups [long-chain FA (LCFA), unsaturated FA (UFA), short-chain FA (SCFA), and medium-chain FA (MCFA)]. 
Table 3. Permanent environmental correlations between a temperature-humidity index (THI) of 25 and THI of 45, 60, and 75

\begin{tabular}{|c|c|c|c|}
\hline \multirow[b]{2}{*}{ Trait } & \multicolumn{3}{|c|}{ THI } \\
\hline & 45 & 60 & 75 \\
\hline Milk (kg) & 0.92 & 0.71 & 0.42 \\
\hline Fat $(\mathrm{kg} \times 100)$ & 0.93 & 0.74 & 0.45 \\
\hline Protein $(\mathrm{kg} \times 100)$ & 0.91 & 0.67 & 0.36 \\
\hline Fat percentage $(\% \times 100)$ & 0.89 & 0.64 & 0.37 \\
\hline Protein percentage $(\% \times 100)$ & 0.84 & 0.46 & 0.11 \\
\hline SCS & 0.87 & 0.48 & 0.07 \\
\hline \multicolumn{4}{|l|}{ Individual FA (g/dL of milk) } \\
\hline $\mathrm{C} 4: 0(\times 1,000)$ & 0.78 & 0.33 & 0.01 \\
\hline C6:0 $(\times 1,000)$ & 0.82 & 0.40 & 0.05 \\
\hline C8:0 $(\times 1,000)$ & 0.84 & 0.43 & 0.05 \\
\hline C10:0 $(\times 100)$ & 0.87 & 0.49 & 0.09 \\
\hline $\mathrm{C} 12: 0(\times 1,000)$ & 0.87 & 0.51 & 0.10 \\
\hline $\mathrm{C} 14: 0(\times 100)$ & 0.87 & 0.51 & 0.13 \\
\hline C16:0 $(\times 100)$ & 0.85 & 0.45 & 0.06 \\
\hline $\mathrm{C} 17: 0(\times 1,000)$ & 0.85 & 0.50 & 0.16 \\
\hline $\mathrm{C} 18: 0(\times 100)$ & 0.78 & 0.35 & 0.01 \\
\hline C18:1 cis-9 $(\times 100)$ & 0.76 & 0.18 & -0.20 \\
\hline \multicolumn{4}{|l|}{ FA $\operatorname{group}^{1}(\mathrm{~g} / \mathrm{dL}$ of milk $)$} \\
\hline UFA $(\times 100)$ & 0.75 & 0.22 & -0.13 \\
\hline SFA $(\times 100)$ & 0.88 & 0.58 & 0.24 \\
\hline MUFA $(\times 1,000)$ & 0.76 & 0.22 & -0.15 \\
\hline PUFA $(\times 100)$ & 0.75 & 0.40 & 0.14 \\
\hline SCFA $(\times 1,000)$ & 0.83 & 0.42 & 0.05 \\
\hline MCFA $(\times 100)$ & 0.86 & 0.48 & 0.08 \\
\hline LCFA $(\times 100)$ & 0.74 & 0.22 & -0.11 \\
\hline
\end{tabular}

${ }^{1} \mathrm{UFA}=$ unsaturated $\mathrm{FA} ; \mathrm{SCFA}=$ short-chain $\mathrm{FA} ; \mathrm{MCFA}=$ mediumchain FA; LCFA = long-chain FA.

(Table 2) and positive genetic covariances between level and slope. However, C18:1 cis-9 had a much larger PE intercept-to-slope variance ratio than SCS and clearly differentiated genetic correlations at high THI within and across traits (Figure 3). The high sensitivity of C18:1 cis-9 to heat stress is a reflection of its high genetic variation between intercept and slope, but also is a consequence of the positive covariance between them. Content of $\mathrm{C} 18: 1$ cis-9 in milk is considered to be a good indicator of energy balance status in early lactation (Bastin et al., 2013), and a high C18:1 cis-9 content in early lactation is associated with body fat mobilization (Bastin et al., 2011) and poorer fertility performance (Bastin et al., 2012). Furthermore, Moore et al. (2005) reported that heat-stressed dairy cows enter a bioenergetic state characterized by a negative energy balance similar to that seen in early lactation and this state likely is independent of lactation stage and, therefore, may limit their milk yield and milk composition synthesis. This study confirms that $\mathrm{C} 18: 1$ cis-9 could be a good milk biomarker for heat stress in dairy cattle. Recently, C18:1 cis-9 data began to become available from milk-recording schemes (i.e., predictions derived from mid-infrared spectrometry in the Walloon region of Belgium). Therefore, the use of this trait in management or genetic programs for heat tolerance or heat-stress management has become an option.

\section{CONCLUSIONS}

Phenotypic and genetic estimates of TD performance differed by trait across THI. Generally, they decreased at high THI for most traits. However, they increased with THI for SCS as well as UFA and its major individual FA. Antagonistic relationships between intercept and slope indicated that ignoring heat tolerance when selecting for most traits would impair adaptation to heat stress. However, high genetic correlations across the THI range suggest no genotype by environment interaction for most traits under the studied conditions. Nevertheless, for SCS, fat yield, and particularly C18:1 cis-9, large genetic variation between THI and heat tolerance in addition to a low genetic correlation between low and high THI suggest that those traits have the greatest sensitivity to hot conditions in a temperate climate. These results support indirectly previously reported findings on the relationship between bioenergetic status of cows and C18:1 cis-9. They also support the use of milk composition (i.e., C18:1 cis-9) as a source of affordable milk biomarker for heat stress. This could show a way to eliminate the major obstacle of inadequate phenotype and weather recording in the future development of both genomic selection and modern management systems for adaptation to and mitigation of heat stress in dairy cattle.

\section{ACKNOWLEDGMENTS}

Hedi Hammami, as a former postdoctoral fellow, and Jérémie Vandenplas, as a former research fellow, acknowledge the support of the National Fund for Scientific Research (Brussels, Belgium) for their fellowships. The first author acknowledges the support of the project GplusE. This project has received funding from the European Union's Seventh Framework Program for Research, technological development and demonstration under grant agreement no. 613689. The views expressed in this publication are the sole responsibility of the author(s) and do not necessarily reflect the views of the European Commission (Brussels, Belgium). The authors thank the Walloon Breeding Association (Ciney, Belgium) and the National Meteorological Institute (Brussels, Belgium) for providing access to cow performance and climate data, respectively. The authors are grateful to University of Liege (SEGI facility, Liege, Belgium) for the use of its NIC3 supercomputer. Editorial help by Suzanne Hubbard (Lanham, MD) is gratefully acknowledged. 

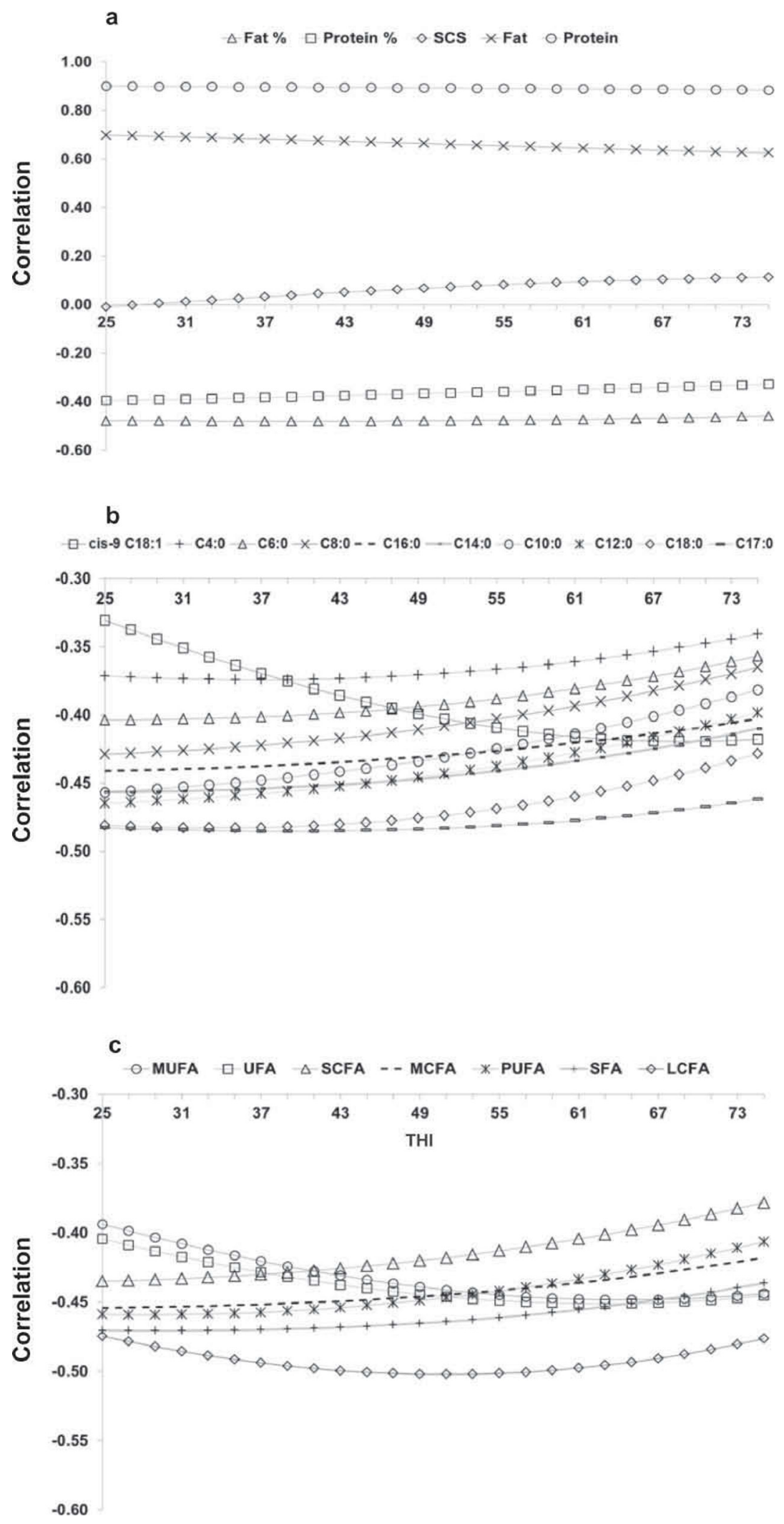

Figure 4. Approximate genetic correlations between test-day milk yield and test-day (a) fat and protein percentages, SCS, and fat and protein yields, (b) individual FA (C18:1 cis-9, C4:0, C6:0, C8:0, C16:0, C14:0, C10:0, C12:0, C18:0, and C17:0), and (c) FA groups [unsaturated FA (UFA), short-chain FA (SCFA), medium-chain FA (MCFA), and long-chain FA (LCFA)] by temperature-humidity index (THI). 


\section{REFERENCES}

Aguilar, I., I. Misztal, and S. Tsuruta. 2009. Genetic components of heat stress for dairy cattle with multiple lactations. J. Dairy Sci 92:5702-5711.

Barber, M. C., R. A. Clegg, M. T. Travers, and R. G. Vernon. 1997. Lipid metabolism in the lactating mammary gland. Biochim. Biophys. Acta 1347:101-126.

Bastin, C., D. P. Berry, H. Soyeurt, and N. Gengler. 2012. Genetic correlations of days open with production traits and contents in milk of major fatty acids predicted by mid-infrared spectrometry. J. Dairy Sci. 95:6113-6121.

Bastin, C., N. Gengler, and H. Soyeurt. 2011. Phenotypic and genetic variability of production traits and milk fatty acid contents across days in milk for Walloon Holstein first-parity cows. J. Dairy Sci. 94:4152-4163.

Bastin, C., H. Soyeurt, and N. Gengler. 2013. Genetic parameters of milk production traits and fatty acid contents in milk for Holstein cows in parity 1-3. J. Anim. Breed. Genet. 130:118-127.

Bohmanova, J., I. Misztal, S. Tsuruta, H. D. Norman, and T. J. Lawlor. 2008. Short communication: Genotype by environment interaction due to heat stress. J. Dairy Sci. 91:840-846.

Boonkum, W., I. Misztal, M. Duangjinda, V. Pattarajinda, S. Tumwarsorn, and J. Sanpote. 2011. Genetic effects on heat stress on milk yield of Thai Holstein crossbreds. J. Dairy Sci. 94:487-492.

Brügemann, K., E. Gernand, U. U. von Borstel, and S. König. 2011 Genetic analyses of protein yield in dairy cows applying random regression models with time-dependent and temperature $\times$ humidity-dependent covariates. J. Dairy Sci. 94:4129-4139.

Calo, L. L., R. E. Mcdowell, L. D. Van Vleck, and P. D. Miller. 1973. Genetic aspects of beef production among Holstein-Friesians pedigree selected for milk production. J. Anim. Sci. 37:676-682.

Carabaño, M. J., K. Bachagha, M. Ramón, and C. Díaz. 2014. Modeling heat stress effect on Holstein cows under hot and dry conditions: Selection tools. J. Dairy Sci. 97:7889-7904.

Chilliard, Y., A. Ferlay, R. M. Mansbridge, and M. Doreau. 2000 Ruminant milk fat plasticity: Nutritional control of saturated, polyunsaturated, trans and conjugated fatty acids. Ann. Zootech. 49:181-205.

Chilliard, Y., C. Martin, J. Rouel, and M. Doreau. 2009. Milk fatty acids in dairy cows fed whole crude linseed, extruded linseed, or linseed oil, and their relationship with methane output. J. Dairy Sci. 92:5199-5211.

Dikmen, S., J. B. Cole, D. J. Null, and P. J. Hansen. 2012. Heritability of rectal temperature and genetic correlations with production and reproduction traits in dairy cattle. J. Dairy Sci. 95:3401-3405.

Finocchiaro, R., J. B. C. H. M. van Kaam, B. Portolano, and I. Misztal. 2005. Effect of heat stress on production of Mediterranean dairy sheep. J. Dairy Sci. 88:1855-1864.

Hammami, H., J. Bormann, N. M'hamdi, H. H. Montaldo, and N. Gengler. 2013. Evaluation of heat stress effects on production traits and somatic cell score of Holsteins in a temperate environment. J. Dairy Sci. 96:1844-1855.

Hammami, H., M. J. Carabaño, B. Logar, M. L. Vanrobays, and N. Gengler. 2014. Genotype $\times$ climate interactions for protein yield using four European Holstein populations. Paper no. 30 in Proc. 10th World Congr. Genet. Appl. Livest. Prod., Vancouver, BC, Canada. https:/asas.org/wcgalp-proceedings.

Hammami, H., B. Rekik, and N. Gengler. 2009. Genotype by environment interaction in dairy cattle. Biotechnol. Agron. Soc. Environ. $13: 155-164$.

Hammami, H., B. Rekik, H. Soyeurt, C. Bastin, J. Stoll, and N. Gengler. 2008. Genotype $\times$ environment interaction for milk yield in
Holsteins using Luxembourg and Tunisian populations. J. Dairy Sci. 91:3661-3671.

Kolmodin, R., and P. Bijma. 2004. Response to mass selection when the genotype by environment interaction is modelled as a linear reaction norm. Genet. Sel. Evol. 36:435-454.

Lambertz, C., C. Sanker, and M. Gauly. 2014. Climatic effects on milk production traits and somatic cell score in lactating Holstein-Friesian cows in different housing systems. J. Dairy Sci. 97:319-329.

Misztal, I., S. Tsuruta, T. Strabel, B. Auvray, T. Druet, and D. H. Lee. 2002. BLUPF90 and related programs (BGF90). Commun. No. 28-07 in Proc. 7th World Congr. Genet. Appl. Livest. Prod., Montpellier, France. INRA, Castanet-Tolosan, France.

Moore, C. E., J. K. Kay, M. J. VanBaale, R. J. Collier, and L. H. Baumgard. 2005. Effect of supplemental conjugated linoleic acids on heat-stressed Brown Swiss and Holstein cows. J. Dairy Sci 88:1732-1740.

NRC. 1971. A Guide to Environmental Research on Animals. Natl Acad. Sci., Washington, DC.

Ravagnolo, O., and I. Misztal. 2000. Genetic component of heat stress in dairy cattle, parameter estimation. J. Dairy Sci. 83:2126-2130.

Renaudeau, D., A. Collin, S. Yahav, V. de Basilio, J. L. Gourdine, and R. J. Collier. 2012. Adaptation to hot climate and strategies to alleviate heat stress in livestock production. Animal 6:707-728.

Renna, M., C. Lussiana, V. Malfatto, A. Mimosi, and L. M. Battaglini. 2010. Effect of exposure to heat stress conditions on milk yield and quality of dairy cows grazing on Alpine pasture. Pages 1338-1348 in Proc. 9th Eur. IFSA Symp., Vienna, Austria. I. Darnhofer and M. Grötzer, ed. Universität für Bodenkultur, Vienna, Austria.

Richardson, C. W., H. D. Johnson, C. W. Gehrke, and D. F. Goerlitz 1961. Effects of environmental temperature and humidity on the fatty acid composition of milk fat. J. Dairy Sci. 44:1937-1940.

Sánchez, J. P., I. Misztal, I. Aguilar, B. Zumbach, and R. Rekaya. 2009. Genetic determination of the onset of heat stress on daily milk production in the US Holstein cattle. J. Dairy Sci. 92:40354045.

Simensen, E. 1976. Milk somatic cells in dairy cows kept on pasture or confined indoors during the summer. Nord. Vet. Med. 28:603-609.

Smith, G. H., B. Grabtree, and R. A. Smith. 1983. Energy metabolism in the mammary gland. Pages 121-140 in Biochemistry of Lactation. T. B. Mepham, ed. Elsevier Sci. Publ. B.V., Amsterdam, the Netherlands,

Soyeurt, H., F. Dehareng, N. Gengler, S. McParland, E. Wall, D. P. Berry, M. Coffey, and P. Dardenne. 2011. Mid-infrared prediction of bovine milk fatty acids across multiple breeds, production systems, and countries. J. Dairy Sci. 94:1657-1667.

Thatcher, W. W., and R. J. Collier. 1986. Effects of climate on bovine reproduction. Pages 301-309 in Current Therapy in Theriogenology: Diagnosis, Treatment, and Prevention of Reproductive Diseases in Small and Large Animals. 2nd ed. D. A. Morrow, ed. W. B. Saunders, Philadelphia, PA.

Wall, E., G. Simm, and D. Moran. 2010. Developing breeding schemes to assist mitigation of greenhouse gas emissions. Animal 4:366376.

Zumbach, B., I. Misztal, S. Tsuruta, J. P. Sanchez, M. Azain, W. Herring, J. Holl, T. Long, and M. Culbertson. 2008. Genetic components of heat stress in finishing pigs: Parameter estimation. J. Anim. Sci. 86:2076-2081.

Zwald, N. R., K. A. Weigel, W. F. Fikse, and R. Rekaya. 2003. Application of a multiple-trait herd cluster model for genetic evaluation of dairy sires from seventeen countries. J. Dairy Sci. 86:376-382. 